\title{
Experimental Study on the use of Bamboo as Structural Reinforcements in RCC Structures
}

\author{
Ms. Pushpanjali Verma \\ M.Tech Student \\ Department of Civil Engineering \\ SHIATS, Prayagaraj \\ Uttar Pradesh, India
}

\author{
Mr. Vipin Mahadeven \\ Assistant Professor, \\ Department of Civil Engineering \\ Rajkiya Engineering College Azamgarh \\ Azamgarh, Uttar Pradesh, India
}

\begin{abstract}
Bamboo is a natural material obtain from plants family. It is fast growing, light weighted, renewable and environment friendly. Bamboo material is very interesting topic in construction for research. Bamboo has good tensile strength; from a study it is found that tensile strength specific weight ratio of bamboo is twenty times more than that of steel.
\end{abstract}

An experimental investigation of bamboo characteristics and bamboo as reinforcement in concrete study is carried out in this paper. Here we have focused on to identify water absorption in bamboo during curing period and flexure strength of bamboo reinforce beam, cracking pattern and other experimental value to step more towards bamboo as alternative to steel.

Keywords-Bamboo, Reinforcement, flexure, compresssion, tension, naturally available construction material.

\section{INTRODUCTION}

In recent year, many researchers around the world have already begun to explore the use of low cost and low energy substitute construction materials. [1]

Among the many possibilities for such substitutions Bamboo, which is one of the fastest growing plants, has great potential. [2] [4]

Bamboo has been used in construction of bridges and houses for thousands of years in Asia. Bamboo takes less energy to harvest and transport. [3]

Bamboo is hygroscopic material thats why it also absorbs moisture from surrounding hence determination of properties, improve over moisture absorption and bamboo reinforcement in concrete beam has been investigated by the authors in the lab and results are presented. [5] [6]

\section{EXPERIMENTAL PROCEDURE}

A mix design of M25 concrete was used to conduct experiment. Bamboo used were collected from Local Market, Lalganj, Azamgarh Uttar Pradesh (India). The age of bamboo used was four and half year. Several tests were conducted to calculate different strength properties which are necessary to find such as compressive strength test, tensile strength test and water absorption test of bamboo specimen in laboratory.

TEST N0. 01

Compressive Strength Test for Bamboo Specimen
In this test we have calculated how much compressive load can a bamboo specimen bear. This test helped out finding either bamboo is suitable as reinforcement in RCC construction or not. For this test we have selected 6 specimen of length 100mm, 3 (AW1, AW2, AW3) are with node and other (AN1, AN2, AN3) are without node.

TABLE 2.1: Compressive Strength of Specimens (without Nodes)

\begin{tabular}{|c|l|c|c|c|}
\hline SPECIMEN & $\begin{array}{l}\text { C.S.AREA } \\
\left(\mathbf{m m}^{2}\right)\end{array}$ & $\begin{array}{l}\text { COMP. } \\
\text { LOAD (KN) }\end{array}$ & $\begin{array}{l}\text { COMP. } \\
\text { STRENGTH } \\
\left(\mathbf{N} / \mathbf{m m}^{2}\right)\end{array}$ & $\begin{array}{l}\text { DEFLECTION } \\
(\mathbf{m m})\end{array}$ \\
\hline AN1 & 2971.168 & 140 & 47.11 & 7 \\
\hline AN2 & 2909.907 & 133.4 & 45.843 & 4 \\
\hline AN3 & 2657.794 & 129.7 & 48.799 & 6 \\
\hline
\end{tabular}

TABLE 2.2: Compressive Strength of Specimens (without Nodes)

\begin{tabular}{|c|c|c|c|c|}
\hline SPECIMEN & $\begin{array}{l}\text { C.S.AREA } \\
\left(\mathbf{m m}^{2}\right)\end{array}$ & $\begin{array}{l}\text { COMP. } \\
\text { LOAD }(\mathbf{K N})\end{array}$ & $\begin{array}{l}\text { COMP. } \\
\text { STRENGTH } \\
\left(\mathbf{N} / \mathbf{m m}^{2}\right)\end{array}$ & $\begin{array}{l}\text { DEFLECTION } \\
(\mathbf{m m})\end{array}$ \\
\hline AW1 & 2510.14 & 128.1 & 51.03 & 5 \\
\hline AW2 & 2563.53 & 120 & 46.81 & 6 \\
\hline AW3 & 2565.90 & 126.7 & 49.378 & 6 \\
\hline
\end{tabular}

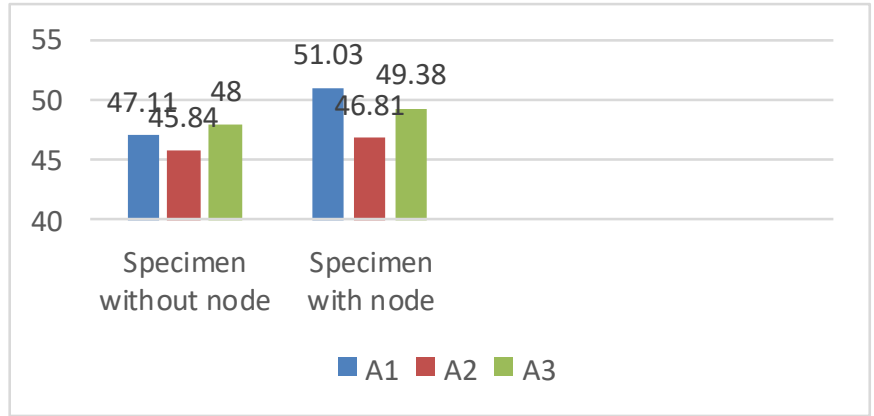

Fig 2.1: Comp. Strength of Bamboo Specimens in MPa
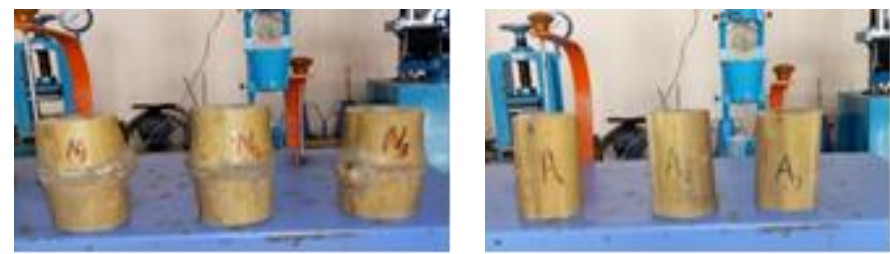

Fig 2.2: Compressive test Specimen with node, Source: Material Testing Lab, REC Azamgarh 


\section{TEST N0. 02}

\section{Tensile Strength Test for Bamboo Specimen}

The tensile test was carried out on bamboo splints to determine the ultimate tensile strength of bamboo. The ultimate tensile strength of bamboo is importance to calculate the maximum allowable tensile stress in bamboo, when bamboo is being used as reinforcement in concrete elements to take the tensile loads. We have taken 5 test specimens namely, A1, A2, A3, A4, A5.

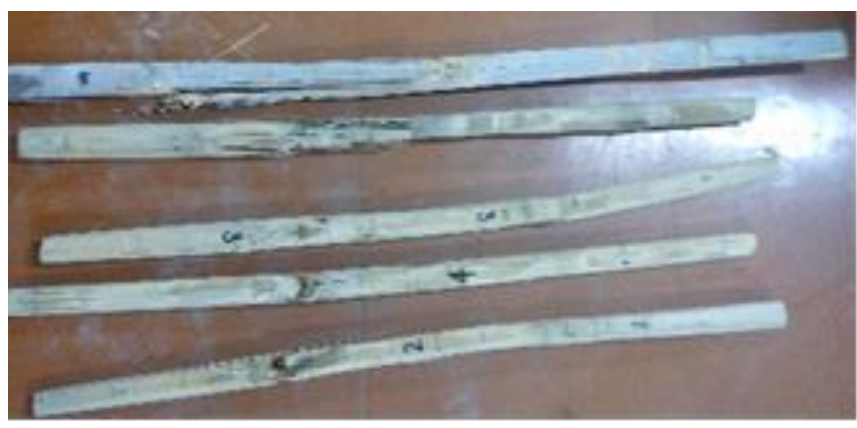

Fig 2.3: Bamboo Specimen for tensile test, Source: Material Testing Lab, IIT BHU

TABLE 2.3: Bamboo splints tensile test

\begin{tabular}{|l|c|c|c|}
\hline Specimen & $\begin{array}{l}\text { Crossectional Area } \\
\left(\mathrm{Mm}^{2}\right)\end{array}$ & $\begin{array}{l}\text { Tensile Load } \\
(\mathrm{Kn})\end{array}$ & $\begin{array}{l}\text { Tensile Strength } \\
\left(\mathrm{N} / \mathrm{Mm}^{2}\right)\end{array}$ \\
\hline A1 & 202 & 33.50 & 164.8515 \\
\hline A2 & 190 & 29.5 & 154.2105 \\
\hline A3 & 186 & 26.80 & 139.7849 \\
\hline A4 & 262 & 47.04 & 179.542 \\
\hline A5 & 224 & 39.24 & 176.428 \\
\hline
\end{tabular}

TABLE 2.4: Bamboo splints tensile test

\begin{tabular}{|l|c|c|c|}
\hline SPECIMEN & $\begin{array}{c}\text { Elongation } \\
(\mathrm{mm})\end{array}$ & Strain & Cracking Load (KN) \\
\hline A1 & 8.50 & 0.0168 & 28.5 \\
\hline A2 & 8.00 & 0.0158 & 26.5 \\
\hline A3 & 8.00 & 0.0158 & 22.5 \\
\hline A4 & 9.32 & 0.0170 & 37.9 \\
\hline A5 & 8.75 & 0.0164 & 36.7 \\
\hline
\end{tabular}

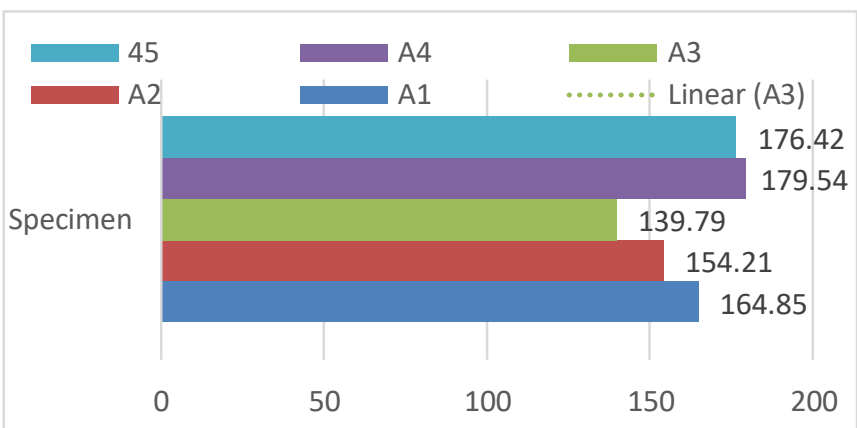

Fig 2.4: Tensile Strength of Bamboo Specimens (MPa)
TEST N0. 03

Water Absorption Test for Bamboo Specimen

Since Bamboo is a hygroscopic material having tending to absorb moisture from air and surroundings. In green concrete bamboo splints absorb moisture and swells, when the concrete becomes dry the bamboo splints contracts and creates spaces between the contacts, the bamboo-concrete bond strength decreases and member fails in bond. Hence water absorption is one of the main drawbacks of bamboo, when it is used as reinforcement in concrete so our main aim is to perform this test to find out percentage of water absorb by bamboo and percentage of volume increase.

We have taken six (WA1, WA2, WA3, W1, W2, W3) sample of bamboo specimen of $50 * 50 \mathrm{~mm} 2$ and let it dry for $24 \mathrm{hrs}$ in an oven. After that the specimen was allowed to cool for 30 minute. 3 Specimen painted with water proof coating (W1, W2, W3) but remaining three were not. Calculation of dimension, weight was made initially. Then all the 6 samples were allowed to soak in water at normal temperature pressure. Reading for changes in dimension and weight was made at every 24-hour interval for next 28 days.

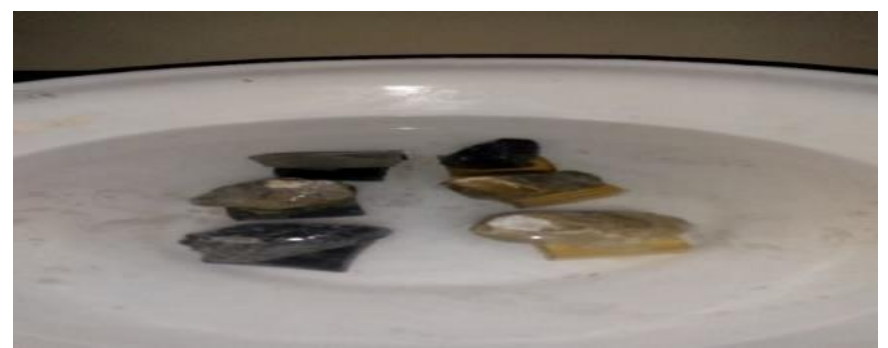

Fig 2.5: Bamboo Specimen into Water, Source: REC Azamgarh Lab

TABLE 2.5: Water absorption of bamboo sample without paint

\begin{tabular}{|c|c|c|c|c|c|c|c|}
\hline DAY & WA1(g) & \%GAIN & WA2(g) & \%GAIN & WA3(g) & \%GAIN & $\begin{array}{c}\text { AVG \% } \\
\text { GAIN }\end{array}$ \\
\hline 1 & 4.273 & $00.0 \%$ & 4.638 & $00.0 \%$ & 4.404 & $00.0 \%$ & $0 \%$ \\
\hline 2 & 6.671 & $56.12 \%$ & 7.61 & $64.08 \%$ & 7.215 & $63.82 \%$ & $61.34 \%$ \\
\hline 3 & 7.429 & $73.85 \%$ & 8.329 & $79.58 \%$ & 7.956 & $80.65 \%$ & $78.03 \%$ \\
\hline 4 & 7.584 & $77.49 \%$ & 8.304 & $79.04 \%$ & 7.923 & $79.91 \%$ & $78.81 \%$ \\
\hline 5 & 7.700 & $80.20 \%$ & 8.289 & $78.71 \%$ & 7.945 & $80.42 \%$ & $79.78 \%$ \\
\hline 6 & 7.783 & $82.15 \%$ & 8.352 & $80.77 \%$ & 7.852 & $78.29 \%$ & $80.40 \%$ \\
\hline 9 & 8.3661 & $95.67 \%$ & 8.920 & $92.15 \%$ & 8.577 & $94.75 \%$ & $94.19 \%$ \\
\hline 11 & 8.493 & $98.75 \%$ & 8.952 & $93.14 \%$ & 8.617 & $95.66 \%$ & $95.85 \%$ \\
\hline 14 & 9.491 & $122.2 \%$ & 10.228 & $120.5 \%$ & 9.778 & $122.3 \%$ & $121.67 \%$ \\
\hline 28 & 10.209 & $138.92 \%$ & 11.647 & $151.00 \%$ & 11.007 & $164.46 \%$ & $151.46 \%$ \\
\hline
\end{tabular}

TABLE 2.6: Water absorption of bamboo sample with paint

\begin{tabular}{|c|c|c|c|c|c|c|c|}
\hline DAY & W1(g) & \%GAIN & W2(g) & \%GAIN & W3(g) & \%GAIN & $\begin{array}{c}\text { AVG \% } \\
\text { GAIN }\end{array}$ \\
\hline 1 & 5.878 & $00.0 \%$ & 4.549 & $00.0 \%$ & 4.557 & $00.0 \%$ & $0 \%$ \\
\hline 2 & 8.405 & $42.69 \%$ & 7.127 & $56.67 \%$ & 6.856 & $50.44 \%$ & $49.93 \%$ \\
\hline 3 & 9.194 & $61.36 \%$ & 7.815 & $73.77 \%$ & 7.616 & $67.12 \%$ & $67.42 \%$ \\
\hline 4 & 9.572 & $62.84 \%$ & 8.079 & $77.59 \%$ & 7.825 & $71.71 \%$ & $70.71 \%$ \\
\hline 5 & 9.836 & $67.33 \%$ & 8.240 & $81.38 \%$ & 7.989 & $75.32 \%$ & $74.68 \%$ \\
\hline 6 & 10.154 & $72.74 \%$ & 8.428 & $85.27 \%$ & 8.046 & $76.56 \%$ & $78.19 \%$ \\
\hline 9 & 10.940 & $91.54 \%$ & 9.182 & $101.8 \%$ & 8.507 & 86.67 & $93.34 \%$ \\
\hline 11 & 11.306 & $92.34 \%$ & 9.558 & $110.8 \%$ & 8.823 & $95.83 \%$ & $99.66 \%$ \\
\hline 14 & 11.689 & $98.86 \%$ & 10.114 & $122.3 \%$ & 9.286 & $103.7 \%$ & $108.29 \%$ \\
\hline 28 & 12.533 & $113.22 \%$ & 10.684 & $134.86 \%$ & 11.209 & $145.97 \%$ & $131.35 \%$ \\
\hline
\end{tabular}




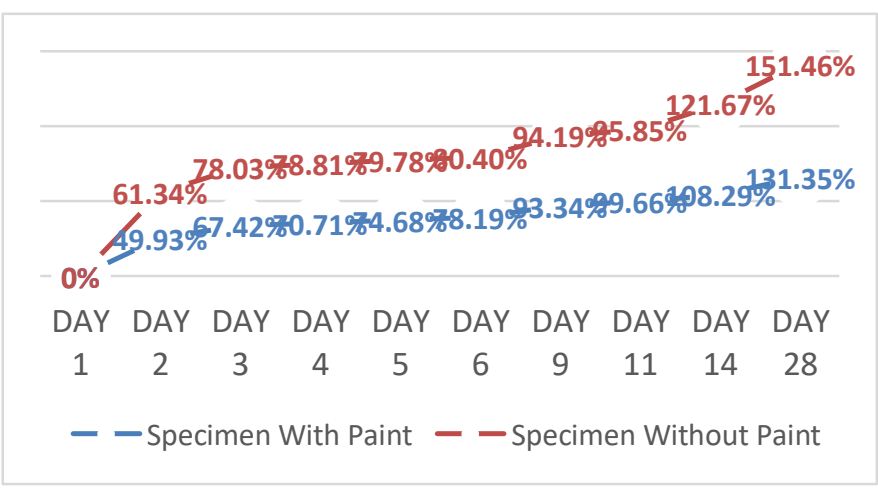

Fig 2.6: Water absorption vs time graph of bamboo specimens.

TABLE 2.7: Calculation of $\mathrm{c} / \mathrm{s}$ area change due to moisture

\begin{tabular}{|c|c|c|c|c|c|c|}
\hline Sample & $\begin{array}{c}\text { Area } \\
\text { before } \\
\text { test } \\
\text { (Without } \\
\text { painted } \\
\left.\text { in } \mathrm{mm}^{2}\right)\end{array}$ & $\begin{array}{c}\text { Area } \\
\text { After } \\
\text { test } \\
(\text { Without } \\
\text { painted } \\
\left.\text { in } \mathrm{mm}^{2}\right)\end{array}$ & $\begin{array}{c}\% \\
\text { change } \\
\text { in area } \\
\left(\mathrm{mm}^{2}\right)\end{array}$ & $\begin{array}{c}\text { Area } \\
\text { before } \\
\text { test } \\
(\text { Painted } \\
\left.\text { in } \mathrm{mm}^{2}\right)\end{array}$ & $\begin{array}{c}\text { Area } \\
\text { After } \\
\text { test } \\
(\text { Painted } \\
\left.\text { in } \mathrm{mm}^{2}\right)\end{array}$ & $\begin{array}{c}\% \\
\text { change } \\
\text { in area } \\
\left(\mathrm{mm}^{2}\right)\end{array}$ \\
\hline A1 & 225 & 239 & 0.062 & 225 & 230 & 0.022 \\
\hline A2 & 225 & 232 & 0.031 & 225 & 229 & 0.017 \\
\hline A3 & 225 & 236 & 0.048 & 225 & 232 & 0.031 \\
\hline
\end{tabular}

Avg \% Area Change in Without Painted

- Avg \% Area Change in Painted2

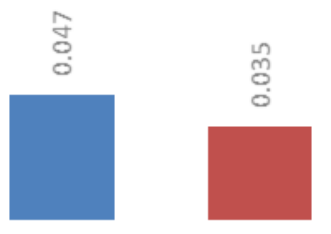

Fig 2.7: \% change in c/s area of bamboo sample

TEST N0. 04

Flexural Strength Test for Bamboo Specimen

Bamboo splints of $12 * 12 \mathrm{~mm} 2$ were used as reinforcement. Bamboo splints were tied in frame of $55 \mathrm{~cm}$ length and within $10 * 10 \mathrm{~cm} 2$. Binding bar is use to tie. Since bamboo absorbs water so a moisture resistance paint was applied over bamboo splints. Bamboo reinforced concrete beam of $150 * 150 * 600 \mathrm{~mm} 3$ were casted with clear cover of $25 \mathrm{~mm}$. For casting beam, we have used mix designed concrete grade of M25. After 28 days of curing, beams were subjected to standard Flexure test and the flexural strength was calculated.

TABLE 2.8: Design mix Grade of M25 concrete ratio.

\begin{tabular}{|c|c|c|c|}
\hline Cement & F.A & C.A & Water \\
\hline $\begin{array}{c}435.409 \\
\mathbf{m}^{\mathbf{3}}\end{array}$ & $\begin{array}{c}653.384 \mathbf{~ K g} / \\
\mathbf{m}^{\mathbf{3}}\end{array}$ & $\begin{array}{c}1173.782 \\
\mathbf{K g} / \mathbf{~ m}^{\mathbf{3}}\end{array}$ & $\begin{array}{c}216.49 \mathbf{~ K g} / \\
\mathbf{m}^{\mathbf{3}}\end{array}$ \\
\hline 1 & 1.5 & 2.696 & 0.497 \\
\hline
\end{tabular}

$150 \mathrm{~m}$

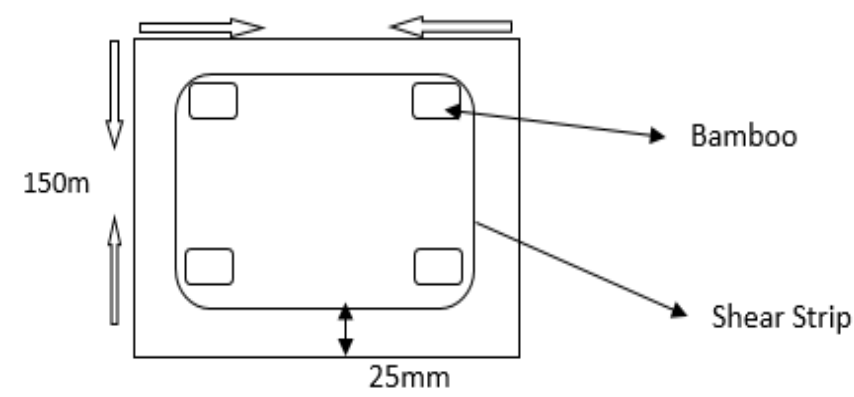

Fig 2.8: Cross sectional detailing of Beam for Flexure

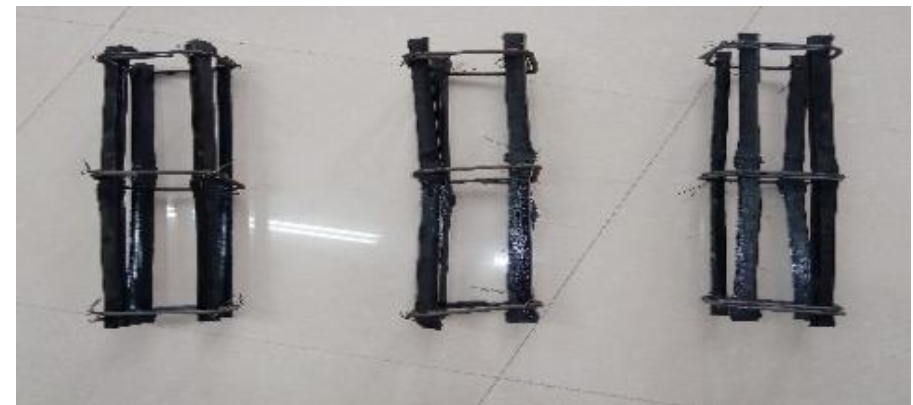

Fig 2.9: Bamboo frame for reinforcement, Source: Material Testing Lab, REC Azamgarh

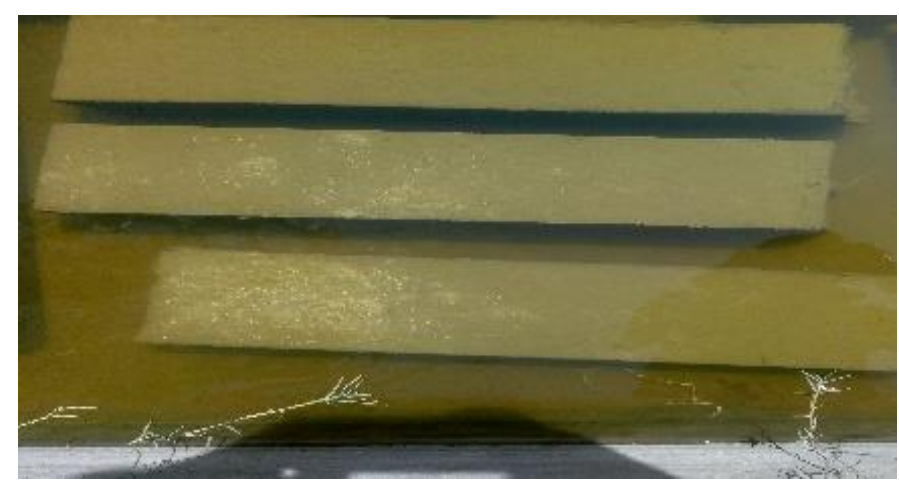

Fig 2.10: Beam during curing, Source: Material Testing Lab, REC Azamgarh

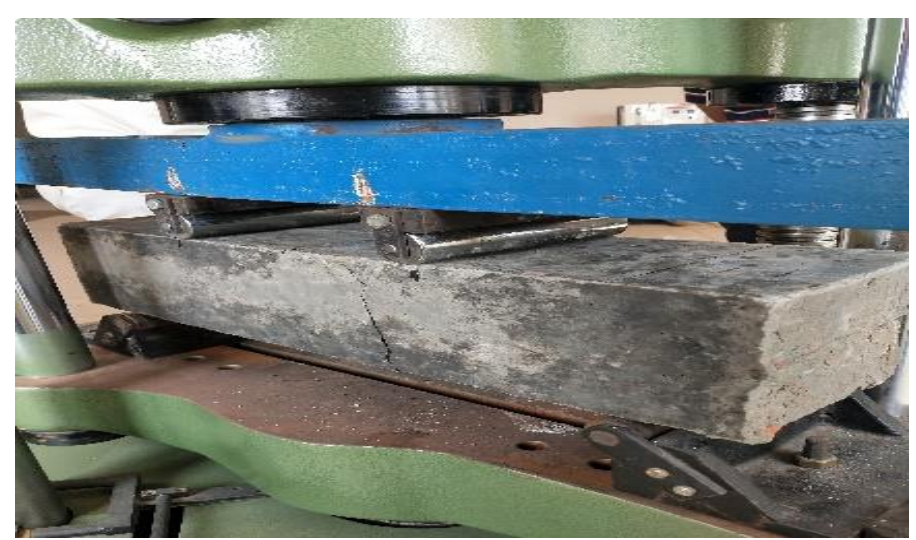

Fig 2.11: Bamboo reinforced Concrete Beam during test 
TABLE 2.9: Flexural strength of BRC beam after 28 days

\begin{tabular}{|c|c|c|}
\hline Sr. No & Test Sample & FLEXURAL STRENGTH $\left(\mathrm{N} / \mathrm{mm}^{2}\right)$ \\
\hline 1 & B1 & 56.36 \\
\hline 2 & B2 & 46.01 \\
\hline 3 & B3 & 49.83 \\
\hline
\end{tabular}

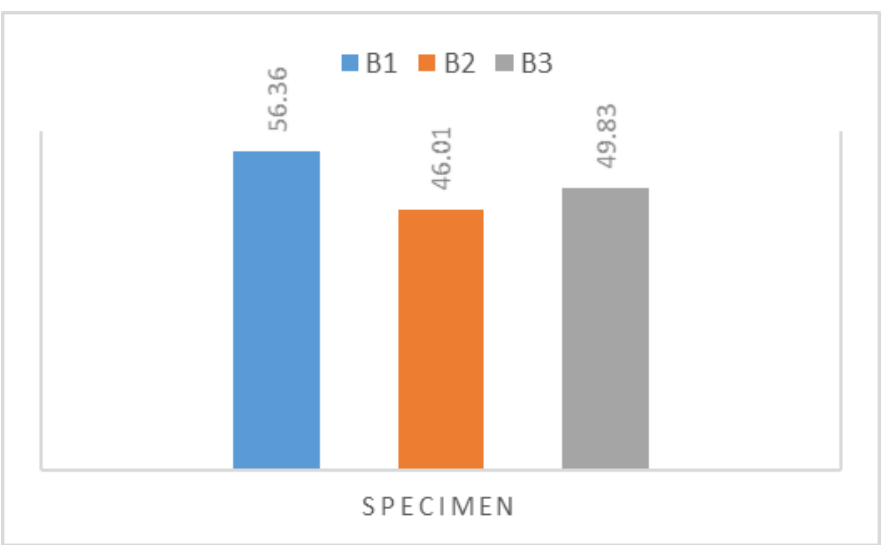

Fig 2.12: Flexural Strength of Test beams in MPa

\section{RESULT AND DISCUSSION}

We have obtained compressive strength of bamboo was good for short building but on application of heavy load, it can fail along the longitudinal direction in form of buckling.

1. Avg Compressive strength with node $=49.07 \mathrm{MPa}$.

2. Avg Compressive strength without node $=47.25$ $\mathrm{MPa}$.

By tensile test, it was found out that bamboo follow brittle failure.

1. Average tensile strength of bamboo specimen $=162.96 \mathrm{MPa}$.

By water absorption experiment results it was found out that water absorption and change in area volume due to absorbed water, both are decreased when coated with moisture resistant paint. That is positive result and helping in maintaining strength of bamboo.

1. Avg \% Area Change (Paint) $=0.047 \%$

2. Avg \% Area Change (Non-Paint) = $0.035 \%$

3. \% by weight of max water absorbed in Painted $=131.55 \%$
4. \% by weight of max water absorbed in Non-Painted $=151.46 \%$

In our flexural strength test, failure in beam is occurs at the mid of beam hence this was flexural type of failure.

1. Avg Flex. strength of Bamboo $=50.73$ $\mathrm{MPa}$

\section{CONCLUSION}

The experimental analysis is done for compressive strength of bamboo specimen. And it was found that compressive strength of bamboo specimen with node has greater strength than that of specimens without node this could be because of additional cross-sectional area at nodes and due to the dense mass present at nodes. Some of the specimen showed an ideal failure by cracking longitudinally but most of them showed a mixed mode of failure where in the specimen cracked as well as got crushed and buckled along length.

As per result an average ultimate tensile strength of bamboo splints is $160 \mathrm{MPa}$ which is comparatively lower than the yield strength of structural steel i.e. 250MPa. But bamboo splints can resist sufficient tensile loads in a concrete flexure element. All the bamboo specimens shown brittle failure.

The water absorption value is decreased by using moisture resistant paint and can help in maintain strength and shrinkage and swelling problem.

Bamboo Reinforced Concrete Beam follows same pattern those in steel reinforcement elements. The ultimate moment is $50.733 \mathrm{MPa}$ i.e. good result for short building. After testing, cracks are developed at the mid span in beam i.e. flexural type failure.

\section{REFERENCES}

[1] American Journal of Engineering Research (AJER) e-ISSN: 23200847 p-ISSN: 2320-0936 By Dinesh Bhonde, P. B. Nagarnaik, D. K. Parbat, U. P. Waghe.

[2] Investigation on properties of bamboo as reinforcing material in concrete by Harish Sakaray et al (2012).

[3] Kawamura, K.(1941). Bamboo reinforced Concrete, Sankaido Syuppan, Japan

[4] K. Ghavami, - Application of Bamboo as a Low-Cost Construction Material, || In Procoft International Bamboo Workshop, Cochin, India, pp. $270-279,1988$.

[5] K. Ghavami, - Ultimate Load Behaviour of Bamboo Reinforced Lightweight Concrete Beams, \| J. Cement Concrete Compos, pp. 281-288, 1995.

[6] Ranendra Nath Bhowmik et al. (2015)/ International Journal of Engineering and Technology (IJET) ISSN (Print): 2319-8613. 